\title{
IN VIVO STUDIES OF 5-HYDROXYINDOLE METABOLISM IN PATIENTS WITH HEPATIC CIRRHOSIS AND IN RATS * $\dagger$
}

\author{
BY ROBERT M. DONALDSON, JR., $\ddagger$ JULIAN ARABEHETY § AND \\ SEYMOUR J. GRAY $\|$ \\ (From the Medical Clinic, Peter Bent Brigham Hospital, and the Department of Medicine, \\ Harvard Medical School, Boston, Mass.)
}

(Submitted for publication December 1, 1958; accepted February 17, 1959)

Widespread interest in 5-hydroxytryptamine (5-HTA) as a biologically active amine and the close association between this substance and malignant carcinoidosis have led to detailed studies of the 5-hydroxyindole pathway of tryptophan metabolism in man and experimental animals (1-3). Tryptophan is apparently hydroxylated to form the serotonin precursor, 5-hydroxytryptophan (5-HTP) $(1,4)$. In the presence of a specific, pyridoxine-dependent decarboxylase, 5-HTP is readily decarboxylated in several tissues to form 5-HTA (5). Monoamine oxidase, which is found principally in gut, lung, liver, kidney and brain, catalyzes the oxidative deamination of 5-HTA to form 5-hydroxyindoleacetic acid (5-HIAA) $(6,7)$.

Since both 5-HTP decarboxylase and monoamine oxidase have been demonstrated in liver tissue in vitro, investigation of 5-hydroxyindole metabolism in patients with hepatic cirrhosis was undertaken. The present report summarizes studies of 5-HTA and 5-HIAA excretion in the urine following the intravenous administration of various 5-hydroxyindole compounds in human subjects with and without hepatic cirrhosis and in rats.

* This work was supported in part by grants from the United States Public Health Service and the Gastrointestinal Fund of the Peter Bent Brigham Hospital.

$\dagger$ This work was presented in part at the annual meeting of the American Gastroenterological Association, May, 1958, Washington, D. C.

$\ddagger$ Research Fellow in Medicine, Harvard Medical School, and Junior Associate in Medicine, Peter Bent Brigham Hospital.

$\S$ Miles-Ames Research Fellow in Medicine, Harvard Medical School, and Assistant in Medicine, Peter Bent Brigham Hospital.

\| Associate Clinical Professor of Medicine, Harvard Medical School, and Physician, Peter Bent Brigham Hospital.

\section{MATERIALS AND METHODS}

1. Endogenous excretion of 5-HIAA in human subjects. The urinary excretion of endogenous 5-HIAA was measured in one or more total 24 hour urine collections obtained from 10 healthy adults, 75 hospitalized patients without hepatic disease, renal disease or known sprue syndrome (8), 35 patients hospitalized with hepatic cirrhosis and two patients with malignant carcinoidosis. None of the subjects had clinical evidence of renal disease. All had 24 hour urine volumes greater than 500 $\mathrm{ml}$. and blood urea nitrogens of less than $20 \mathrm{mg}$. per cent. None of the subjects were receiving phenothiazine derivatives (9) or a banana diet (10) during the period of study.

2. Intravenous administration of 5-hydroxyindolc compounds to human subjects. Studies of the urinary excretion of 5-HTA and 5-HIAA following the intravenous administration of various 5-hydroxyindole compounds were carried out in 21 control subjects, in 20 patients with decompensated hepatic cirrhosis and in seven patients with surgically documented extrahepatic obstruction with no evidence of significant intrahepatic disease. 5-HTP 1 $(0.33 \mathrm{mg}$. of $\mathrm{L}$ form per $\mathrm{Kg}$.) or 5-HIAA $(0.2 \mathrm{mg}$. per $\mathrm{Kg}$.) was diluted in 250 to $300 \mathrm{ml}$. of isotonic saline and administered over a period of one hour in the early morning to subjects in the fasting state. 5-HTA 2 ( 0.2 mg. of 5-HTA base per $\mathrm{Kg}$.) was diluted in 500 to $1,000 \mathrm{ml}$. of isotonic saline and administered intravenously over a period of two to four hours. At least 48 hours was allowed to elapse between infusions whenever the same subject received more than one intravenous infusion. The total urinary excretion was collected in six hour aliquots for at least 24 hours before and after each intravenous infusion. Results were calculated as percentage of the administered 5-hydroxyindole compound which was recovered in the urine as 5-HIAA or 5-HTA.

3. Studies in rats. The urinary excretion of 5-HIAA and 5-HTA following the administration of various 5-hydroxyindole compounds was studied in male SpragueDawley rats weighing 300 to $500 \mathrm{Gm}$. The animals were maintained on regular laboratory Purina chow and water ad libitum. Each rat served as his own control. Sodium orthoaminobenzoate $(\mathrm{NaOAB}), 1 \mathrm{Gm}$. per $\mathrm{Kg}$.

1 Administered as 5-hydroxy-DL-tryptophan, supplied by Abbott Laboratories.

2 Administered as serotonin creatinine sulfate, supplied by Abbott Laboratories. 
TABLE I

The endogenous urinary excretion of 5-hydroxyindoleacetic acid in human subjects

\begin{tabular}{lcccc}
\hline \hline \multicolumn{1}{c}{ Group } & $\begin{array}{c}\text { Number of } \\
\text { subjects }\end{array}$ & $\begin{array}{c}\text { Number of } \\
\text { determinations }\end{array}$ & Range & Average \\
\hline Healthy adults & & & mg./24 hrs. & mg./24 hrs. \\
Hospitalized patients without liver or renal & 10 & 27 & $2.2-6.7$ & $4.0 \pm 1.4$ \\
$\quad$ disease & 75 & 132 & $1.5-12.4$ & $4.3 \pm 2.4$ \\
Hepatic cirrhosis without encephalopathy & 19 & 39 & $1.9-13.4$ & $6.7 \pm 3.3$ \\
Hepatic cirrhosis with encephalopathy & 16 & 34 & $2.1-13.7$ & $6.1 \pm 3.1$ \\
Carcinoid syndrome & 2 & 12 & $45-360$ & $154 \pm 78$ \\
\hline
\end{tabular}

body weight, was injected intraperitoneally together with a given 5-hydroxyindole compound. Since $\mathrm{NaOAB}$ is rapidly conjugated to form a glucuronide, excessive amounts were administered in this study in an attempt to inhibit competitively the conjugation of serotonin. At least 48 hours before and again 48 hours after $\mathrm{NaOAB}$ was injected together with the 5-hydroxyindole compound, each rat received the same dose of the 5-hydroxyindole compound together with an equivalent amount of sodium chloride. The 5-hydroxyindoles administered in this fashion included 5-HTP ( $25 \mathrm{mg}$. of the $\mathrm{L}$ form per $\mathrm{Kg}$.), 5-HTA (25 mg. of the base per $\mathrm{Kg}$.) and 5-HIAA (20 mg. per $\mathrm{Kg}$.). The animals were kept in metabolic cages and the total urinary excretion was collected separate from feces for 24 hours after each injection.

4. Methods. Aliquots of all urine specimens were kept frozen until analyzed. The urinary excretion of 5-HIAA was measured by the colorimetric method of Udenfriend, Titus and Weissbach (11). Urine samples containing more than $25 \mu \mathrm{g}$. per ml. of 5-HIAA were appropriately diluted. The 5-HTA content of urine was estimated fluorimetrically by a modification (12) of the method of Udenfriend, Weissbach and Clark (13). All determinations were carried out in duplicate and were repeated whenever the results varied more than 10 per cent in the duplicate samples. The accuracy of all urine collections was estimated by measurement of urinary excretion of creatinine (14). Paper chromatograms of urinary indoles were prepared by the method of Jepson (15).

\section{RESULTS}

\section{Studies in human subjects}

Results of the urinary excretion of endogenous 5-HIAA are summarized in Table I. The average excretion of 5-HIAA in patients with hepatic cirrhosis with or without evidence of encephalopathy was not significantly greater than that observed in healthy adults or patients without liver disease. The two subjects with metastatic carcinoid tumors excreted strikingly increased amounts of 5-HIAA in the urine. 5-HTA was present in small amounts in the two carcinoid patients but was never observed in other subjects unless they had received intravenous 5 -HTP.

When 5-HTP was administered to control subjects an average of 32 per cent (13 to 42 per cent) of the administered 5-HTP was recovered in the urine as 5-HIAA (Table II). The recovery of administered 5-HTP as urinary 5-HIAA averaged 62 per cent (25 to 105 per cent) among cirrhotic subjects (Table II). The difference between the two groups is significant $(p=<0.001)$. Flapping tremors were noted in all six of the cir-

TABLE II

Summary of studies of 5-hydroxyindole metabolism in human subjects

\begin{tabular}{lcccc}
\hline \hline Group & $\begin{array}{c}\text { Number of } \\
\text { subjects }\end{array}$ & $\begin{array}{c}\text { Compound } \\
\text { administered }\end{array}$ & $\begin{array}{c}\text { Compound } \\
\text { measured } \\
\text { in urine }\end{array}$ & $\begin{array}{c}\text { Percentage of } \\
\text { administered } \\
\text { compound } \\
\text { in urine }\end{array}$ \\
\hline Controls & 21 & 5-HTP & 5-HIAA & S.D. \\
Cirrhosis & 20 & 5-HTP & 5.3 \\
Obstruction & 7 & 5-HTP & 5-HIAA & $31 \pm 19.2$ \\
Controls & 9 & 5-HTP & 5-HTA & $11 \pm 4.0$ \\
Cirrhosis & 8 & 5-HTP & 5-HTA & $15 \pm 7.8$ \\
Controls & 3 & 5-HTA & 5-HIAA & $59 \pm 10.1$ \\
Cirrhosis & 3 & 5-HTA & 5-HIAA & $60 \pm 1.1$ \\
Controls & 7 & 5-HIAA & 5-HIAA & $53 \pm 7.1$ \\
Cirrhosis & 6 & 5-HIAA & 5-HIAA & $64 \pm 15.5$ \\
\hline
\end{tabular}


TABLE III

The effect of sodium orthoaminobenzoate ( $N a O A B)$ on the recovery of administered 5-hydroxyindole compounds in rats

\begin{tabular}{|c|c|c|c|c|}
\hline $\begin{array}{l}\text { Number of } \\
\text { rats }\end{array}$ & $\begin{array}{l}\text { 5-Hydroxyindole } \\
\text { administered }\end{array}$ & $\begin{array}{l}\text { Additional } \\
\text { substance } \\
\text { administered }\end{array}$ & $\begin{array}{l}\text { \% of administered } \\
\text { 5-hydroxyindole } \\
\text { recovered as } \\
\text { urinary 5-HIAA }\end{array}$ & $\begin{array}{l}\text { Urinary } \\
\text { creatinine }\end{array}$ \\
\hline $\begin{array}{l}9 \\
9 \\
9 \\
5 \\
5 \\
5 \\
9 \\
9\end{array}$ & $\begin{array}{l}\text { 5-HTP } \\
\text { 5-HTP } \\
\text { 5-HTP } \\
\text { 5-HTA } \\
\text { 5-HTA } \\
\text { 5-HTA } \\
\text { 5-HIAA } \\
\text { 5-HIAA }\end{array}$ & $\begin{array}{l}\mathrm{NaCl} \\
\mathrm{NaOAB} \\
\mathrm{NaCl} \\
\mathrm{NaCl} \\
\mathrm{NaOAB} \\
\mathrm{NaCl} \\
\mathrm{NaCl} \\
\mathrm{NaOAB}\end{array}$ & $\begin{array}{c} \pm S . D . \\
55.2 \pm 8.8 \\
83.5 \pm 7.9 \\
51.9 \pm 9.1 \\
38.2 \pm 7.4 \\
68.0 \pm 10.5 \\
39.2 \pm 9.5 \\
76.0 \pm 11.8 \\
71.0 \pm 12.2\end{array}$ & $\begin{array}{c} \pm S . D . \\
22.6 \pm 3.2 \\
23.7 \pm 4.6 \\
23.1 \pm 3.8 \\
20.8 \pm 4.3 \\
22.6 \pm 3.9 \\
20.9 \pm 3.6 \\
25.0 \pm 4.1 \\
25.0 \pm 2.9\end{array}$ \\
\hline
\end{tabular}

rhotic subjects in whom the recovery of 5-HTP as urinary 5-HIAA exceeded 70 per cent. Four of these subjects were confused or stuporous, and frank hepatic coma was present in one. The recovery of administered 5-HTP as urinary 5-HIAA in patients with extrahepatic biliary tract obstruction was not different from that observed in control subjects (Table II). The differences in recoveries in the three groups are summarized in Figure 1. 5-HTP was administered on more than one occasion to four control and two cirrhotic subjects. Reproducible recoveries of urinary 5-HIAA were obtained in each of these subjects. The recoveries of administered 5-HTP as urinary 5-HTA in control subjects did not differ from those observed in patients with hepatic cirrhosis (Table II). The average urine volume and creatinine excretion following 5-HTP administration was not different in the two groups.

The intravenous administration of $5-\mathrm{HTP}$ resulted in mild nausea lasting for 10 to 60 minutes in nearly all of the subjects studied. A transient episode of vomiting occurred in only two subjects. None experienced diarrhea. In the cirrhotic patients with impending or frank hepatic coma, administration of 5-HTP had no obvious clinical effect on the flapping tremors or mental state.

When 5-HTA was administered to control and cirrhotic subjects significant amounts of 5-HTA were not found in the urine. The recoveries of administered 5-HTA and 5-HIAA as urinary 5-HIAA were not different in the control and cirrhotic subjects (Table II). Intravenous infusion of 5-HTA resulted in venospasm with local pain and slowing of the infusion, but produced no systemic effects.
No consistent differences were observed in paper chromatograms of indolic compounds which were prepared from the urines of control and cirrhotic subjects who had received 5-hydroxyindole compounds intravenously.

\section{Studies in rats}

The results of intraperitoneal administration of 5-hydroxyindole compounds to rats together with $\mathrm{NaOAB}$ or sodium chloride as a control are summarized in Table III and in Figure 2. In nine rats, the administration of $\mathrm{NaOAB}$ together with 5 -HTP resulted in a significantly $(\mathrm{p}=<0.001)$ greater excretion of urinary 5-HIAA than was observed when 5-HTP was administered together

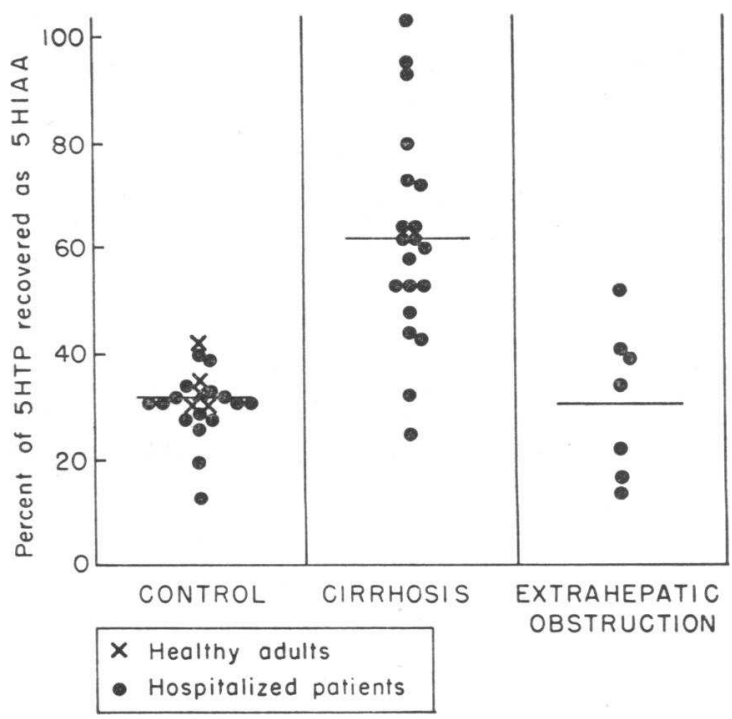

Fig. 1. Recovery of Administered 5-HTP as Urinary 5-HIAA in Human Subjects 


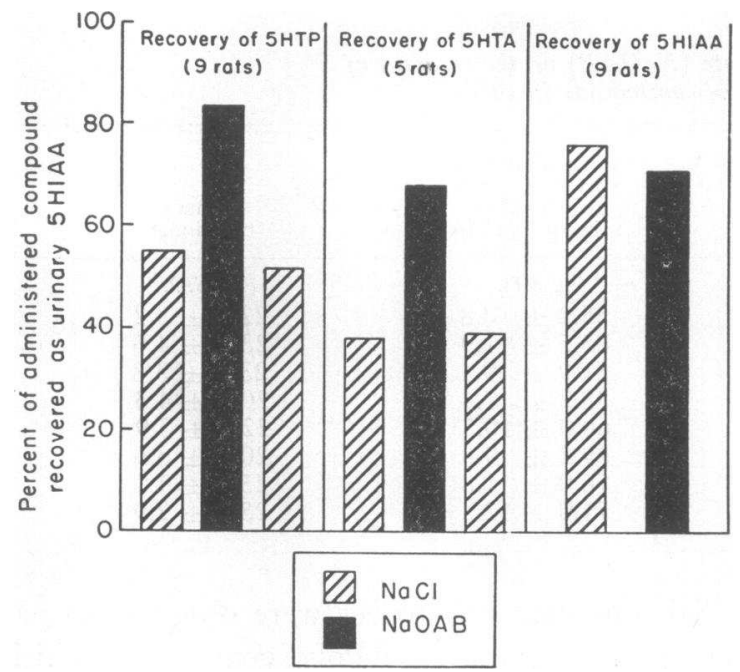

Fig. 2. The Effect of Sodium Orthoaminobenzoate (NaOAB) on the Metabolism of 5-Hydroxyindole Compounds in RATS

with $\mathrm{NaCl}$. The urinary excretion of 5-HTA was consistently diminished when $\mathrm{NaOAB}$ was administered together with 5-HTP. Addition of $\mathrm{NaOAB}$ directly to urine did not interfere with the measurement of 5-HTA or 5-HIAA.

Only five of 21 rats survived the simultaneous intraperitoneal injection of 5-HTA and $\mathrm{NaOAB}$ or $\mathrm{NaCl}$. In general the combination of 5-HTA and $\mathrm{NaOAB}$ proved fatal more often than 5 -HTA and $\mathrm{NaCl}$. Focal areas of necrosis in the kidneys and pulmonary edema were regularly observed at necropsy. In the five surviving rats the administration of 5-HTA together with $\mathrm{NaOAB}$ resulted in a significantly $(\mathrm{p}<0.001)$ greater urinary excretion of 5-HIAA than was observed following the injection of 5-HTA with $\mathrm{NaCl}$. Significant amounts of 5-HTA were not found in the urine.

In nine rats the urinary excretion of 5-HIAA was not altered when 5-HIAA was administered intraperitoneally with $\mathrm{NaOAB}$ or $\mathrm{NaCl}$. In all of the rats studied the urinary excretion of creatinine remained constant throughout all the experiments.

\section{DISCUSSION}

No striking alteration was observed in the urinary excretion of endogenous 5-HIAA in the patients with hepatic cirrhosis whether or not impending or frank hepatic coma was present. It has been suggested that 5 -HIAA excretion might be diminished in cirrhotic patients as a result of impaired formation of 5-HTP in the liver, and, on this basis, a deficiency of serotonin has been postulated in the pathogenesis of hepatic coma (16). The site of tryptophan hydroxylation, however, is as yet unknown, and there is no evidence that significant formation of 5-HTP from tryptophan occurs in the liver (4). The data presented here do not support the concept that 5-HIAA excretion may be decreased in patients with hepatic cirrhosis. Why the urinary excretion of endogenous 5-HIAA is not significantly different in cirrhotic and control subjects while the metabolism of exogenous 5-HTP appears to be altered in hepatic cirrhosis remains unexplained. It is possible that the urinary excretion of 5-HIAA after the administration of 5-HTP may not represent a true reflection of endogenous 5-hydroxyindole metabolism in patients with hepatic cirrhosis.

The recoveries of 5-HIAA in the urine of control subjects following the administration of 5-HTP, 5-HTA and 5-HIAA are similar to those previously reported in normal humans (3). It would appear, however, that the metabolism of exogenous 5-HTP may be altered in patients with hepatic cirrhosis. When 5-HTP was administered to a group of cirrhotic patients the resulting excretion of 5-HIAA in the urine was greater than that observed in control subjects and in patients with extrahepatic biliary tract obstruction. The cirrhotic patients selected for this study were all hospitalized primarily because of liver disease. All were jaundiced or had ascites. Although there was no distinct correlation between the severity of liver disease and the recovery of administered 5-HTP as urinary 5-HIAA, the six cirrhotic patients with the greatest urinary excretion of 5-HIAA following 5-HTP administration all showed clinical evidence of impending or frank hepatic coma.

There are several possible explanations for the greater than normal recovery of urinary 5-HIAA observed in cirrhotic patients after intravenous infusion of 5-HTP. It would appear that 5-HIAA metabolism is probably not altered in hepatic cirrhosis since the recoveries of urinary 5-HIAA after the administration of exogenous 5-HIAA were similar in control and cirrhotic subjects. Whether or not the metabolism of administered 5-HTA is 
altered in patients with cirrhosis of the liver is not clear from this study. Because of venous spasm and pain at the site of infusion, 5-HTA was infused at slow and variable rates to only a few subjects. Since the urinary excretion of 5-HIAA after 5-HTP administration was similar in control subjects and patients with extrahepatic biliary tract obstruction, it seems unlikely that diminished excretion of 5-hydroxyindole compounds in the bile would play a role in the altered metabolism of exogenous 5-HTP observed in patients with hepatic cirrhosis. Although the D-form of 5-HTP may be oxidized by D-amine oxidase in vitro (6), the amount of 5-HIAA which may thus be produced in vivo from D-5-HTP is as yet unknown. The possibility exists, nevertheless, that the metabolism of the $\mathrm{D}$ form of 5-HTP might be altered in hepatic decompensation in such a way as to explain the results obtained in cirrhotic subjects. The data presented in this study, however, do not provide evidence for evaluation of this possibility.

Incubation of 5-hydroxyindole compounds with liver in vitro and chromatographic examination of urinary indoles excreted by carcinoid patients and by animals infused with 5-hydroxyindole compounds suggest that 5-HTA may be metabolized by mechanisms other than oxidative deamination $(2,4,17-20)$. In vitro studies have demonstrated conjugation of 5-HTA in the liver to form serotonin-o-sulfate (17). The formation of serotonin$o$-glucuronide has been demonstrated in vivo in animals after the administration of 5-HTA $(19,20)$.

From the above studies it appears reasonable to postulate that the greater than normal excretion of urinary 5-HIAA following the infusion of 5-HTP in hepatic cirrhosis may be a result of impaired conjugation of 5-HTA. If hepatic conjugation of 5-HTA were impaired, more 5-HTA might be available for metabolism of 5-HIAA. The effect of sodium orthoaminobenzoate $(\mathrm{Na}$ $\mathrm{OAB}$ ) on the excretion of 5-HIAA following the administration of 5-HTP or 5-HTA to rats is of interest in this regard. $\mathrm{NaOAB}$ is rapidly conjugated to form a glucuronide (21), and when present in great excess may impair the formation of other glucuronides. Administration of $1 \mathrm{Gm}$. of $\mathrm{NaOAB}$ per $\mathrm{Kg}$. body weight to rats results in a maximal urinary excretion of glucuronic acid
(22). In vitro studies suggest that the formation of glucuronide conjugates may be competitively inhibited by the presence of $\mathrm{NaOAB}$ or similar compounds (23).

The data indicate that in the presence of excess $\mathrm{NaOAB}$ the urinary excretion of 5-HIAA following the administration of 5-HTP or 5-HTA is significantly greater than that observed when these 5-hydroxyindole compounds are administered alone. $\mathrm{NaOAB}$ appeared to have no effect on the metabolism of exogenous 5-HIAA in these animals. The data presented do not demonstrate that $\mathrm{NaOAB}$ administration results in diminished hepatic conjugation of 5-HTA, nor has impairment of 5-HTA conjugation been shown in patients with hepatic cirrhosis. These studies, however, indirectly support the concept that 5-HTA conjugation may occur in the liver and are consistent with the hypothesis that with impairment of 5-HTA conjugation, larger amounts of 5-HTA may be available for metabolism to 5-HIAA.

\section{SUMMARY}

1. The urinary excretion of 5-hydroxyindoleacetic acid and 5-hydroxytryptamine was studied in patients with decompensated hepatic cirrhosis, control subjects and patients with extrahepatic biliary tract obstruction following the intravenous administration of 5-hydroxytryptophan, 5-hydroxytryptamine and 5-hydroxyindoleacetic acid. The recovery of administered 5-hydroxytryptophan as urinary 5-hydroxyindoleacetic acid was significantly greater in patients with cirrhosis than that observed in control subjects or patients with biliary tract obstruction.

2. The administration of excesses of sodium orthoaminobenzoate together with 5-hydroxytryptophan or 5-hydroxytryptamine to rats resulted in a significantly greater urinary excretion of 5-hydroxyindoleacetic acid than was observed when these compounds were administered together with sodium chloride.

3. The data indirectly support the concept that 5-hydroxytryptamine conjugation may occur in the liver and suggest that in the presence of excesses of 5-hydroxytryptophan, 5-hydroxytryptamine conjugation may be impaired in hepatic cirrhosis. 


\section{ACKNOWLEDGMENTS}

The authors wish to gratefully acknowledge the invaluable assistance of Doctors Rudi Schmid, Dale Friend and Thomas Warthin.

\section{REFERENCES}

1. Udenfriend, S., Titus, E., Weissbach, H., and Peterson, R. E. Biogenesis and metabolism of 5-hydroxyindole compounds. J. biol. Chem. 1956, 219, 335.

2. Udenfriend, S., Weissbach, H., and Bogdanski, D. F. Increase in tissue serotonin following administration of its precursor 5-hydroxytryptophan. J. biol. Chem. 1957, 224, 803.

3. Davidson, J., Sjoedsma, A., Loomis, L. N., and Udenfriend, S. Studies with the serotonin precursor, 5-hydroxytryptophan, in experimental animals and man. J. clin. Invest. 1957, 36, 1594.

4. Dalgliesh, C. E., and Dutton, R. W. On the site of formation of 5-hydroxytryptophan. Biochem. J. 1957, 65, $21 \mathrm{P}$.

5. Clark, C. T., Weissbach, H., and Udenfriend, S. 5-Hydroxytryptophan decarboxylase: Preparation and properties. J. biol. Chem. 1954, 210, 139.

6. Freter, K., Weissbach, H., Udenfriend, S., and Witkop, B. Biochemical and pharmacological studies with D- and L-5-hydroxytryptophan. Proc. Soc. exp. Biol. (N. Y.) 1957, 94, 725.

7. Weissbach, H., Redfield, B. G., and Udenfriend, S. Soluble monoamine oxidase: Its properties and actions on serotonin. J. biol. Chem. 1957, 229, 953.

8. Kowlessar, O. D., Williams, R. C., Law, D. H., and Sleisenger, M. H. Urinary excretion of 5-hydroxyindolacetic acid in diarrheal states, with special reference to nontropical sprue. New Engl. J. Med. 1958, 259, 340.

9. Ross, G., Weinstein, I. B., and Kabakow, B. The influence of phenothiazine and some of its derivatives on the determination of 5-hydroxyindoleacetic acid in urine. Clin. Chem. 1958, 4, 66.

10. Anderson, J. A., Ziegler, M. R., and Doeden, D. Banana feeding and urinary excretion of 5-hydroxyindoleacetic acid. Science 1958, 127, 236.
11. Udenfriend, S., Titus, E., and Weissbach, H. The identification of 5-hydroxy-3-indoleacetic acid in normal urine and a method for its assay. J. biol. Chem. 1955, 216, 499.

12. Bogdanski, D. F., Pletscher, A., Brodie, B. B., and Udenfriend, S. Identification and assay of serotonin in brain. J. Pharmacol. exp Ther. 1956, 117, 82.

13. Udenfriend, S., Weissbach, H., and Clark, C. T. The estimation of 5-hydroxytryptamine (serotonin) in biological tissues. J. biol. Chem. 1955, 215, 337.

14. Bonsnes, R. W., and Taussky, H. H. On the colorimetric determination of creatinine by the Jaffe reaction. J. biol. Chem. 1945, 158, 581.

15. Jepson, J. B. Paper chromatography of urinary indoles. Lancet 1955, 2, 1009.

16. Bessman, S., Merlis, J. K., and Borges, F. Effect of 5-hydroxytryptophane upon electroencephalogram in hepatic coma. Proc. Soc. exp. Biol. (N. Y.) 1957, 95, 502.

17. Snow, P. J. D., Lennard-Jones, J. E., Curzon, G., and Stacey, R. S. Humoral effects of metastasizing carcinoid tumors. Lancet 1955, 2, 1004.

18. Chadwick, P. T., and Wilkinson, J. H. The formation of 5-hydroxytryptamine-o-sulphate by ratliver homogenates. Biochem. J. 1958, 68, 1 P.

19. McIsaac, W. M., and Page, I. H. New metabolites of serotonin in carcinoid urine. Science 1958, 128, 537.

20. Weissbach, H., Redfield, B. G., and Udenfriend, S. Serotonin-o-glucuronide: An alternate route of serotonin metabolism. Fed. Proc. 1958, 17, 418.

21. Williams, R. T. Detoxication Mechanisms. New York, John Wiley and Sons, Inc., p. 105.

22. Schmid, R., Axelrod, J., Hammaker, L., and Swarm, R. L. Congenital jaundice in rats, due to a defect in glucuronide formation. J. clin. Invest. 1958, 37, 1123.

23. Axelrod, J., Inscoe, J. K., and Tomkins, G. M. Enzymatic synthesis of $\mathrm{N}$-glucosyluronic acid conjugates. J. biol. Chem. 1958, 232, 835. 